\title{
Pediatric Femoral Hernia
}

\author{
Yadav RP, ${ }^{1}$ Agrawal CS, ${ }^{1}$ Adhikary S, ${ }^{1}$ Regmi R, ${ }^{1}$ Gupta RK,' Sapkota G' \\ 'Department of Surgery, BPKIHS, Dharan, Nepal
}

\begin{abstract}
Pediatric femoral hernias account for less than $1 \%$ of all groin hernias. Pediatric femoral hernias are rather uncommon more so in males, often overlooked, misdiagnosed and treated as inguinal hernia. Femoral hernia masquerading as inguinal hernia in a seven year old male is reported along with review of relevant literature.
\end{abstract}

Key Words: children, femoral, hernia, misdiagnosed

\section{INTRODUCTION}

A femoral hernia $(\mathrm{FH})$ is defined as protrusion of abdominally contains (viscera, omentum, fat) crossing the femoral hiatus. ${ }^{1}$ The first case of $\mathrm{FH}$ in children was described in 1827 by Cooper, followed by infrequent subsequent publications confirming its rare occurrence in infancy. ${ }^{2-6}$ They account for less than $1 \%$ of all groin hernias in children. 2,6 Many pediatric surgeons and most general surgeons would have a limited experience with this type of hernia in children. ${ }^{2,5,7,8}$ Because these hernias are so uncommon, they are often overlooked, misdiagnosed or even treated as inguinal hernias. ${ }^{9} \mathrm{We}$ report a case of a femoral hernia to bring increased awareness for such an uncommon condition.

\section{CASE REPORT}

A seven year old male child presented with history of occasional swelling in right inguinal region since one year of age. The swelling used to appear on straining or coughing and disappear spontaneously. There was history of constipation but not definitive cause was found. He had no history of abdominal pain or vomiting. No history of similar complaints in other siblings. There was no history of surgery in the past. On examination, the child was of average built with scaphoid abdomen. $\mathrm{He}$ had visible swelling in the right inguinal region which increased in size on coughing and straining (Figure 1). Left inguinal region and both scrotum were normal. A clinical diagnosis of right congenital indirect inguinal hernia was made and the patient was planned for herniotomy. On exploration however, no hernial sac was found in the inguinal canal. Further dissection of the posterior wall of the inguinal canal revealed a thick hernial sac and fatty tissue extending into the femoral canal (Figure 2). A formal Mcvay hernia repair utilizing the conjoint tendon and cooper's ligament was performed. The child had an uneventful postoperative

\author{
Correspondence: \\ Dr. Rohit Prasad Yadav \\ Department of Surgery, \\ BPKIHS, Dharan, Nepal \\ Phone: +977-25-525555 Ext. 2047 \\ Email: yadavrohitl@yahoo.com
}


recovery and was discharged on second day following the surgery. At a follow up of thirteen months there is no evidence of recurrence.

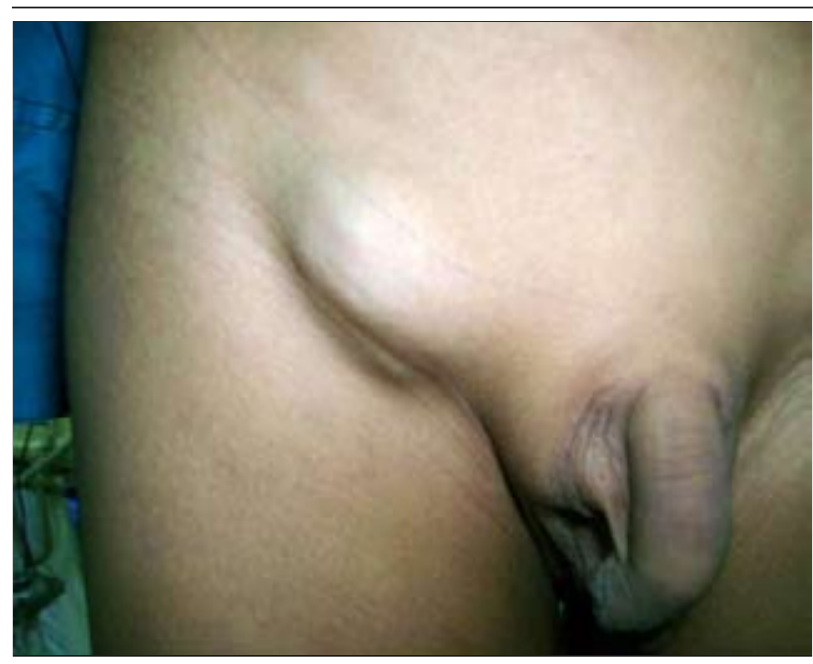

Figure 1. Clinical photograph showing a typical bulge of inguinal hernia.

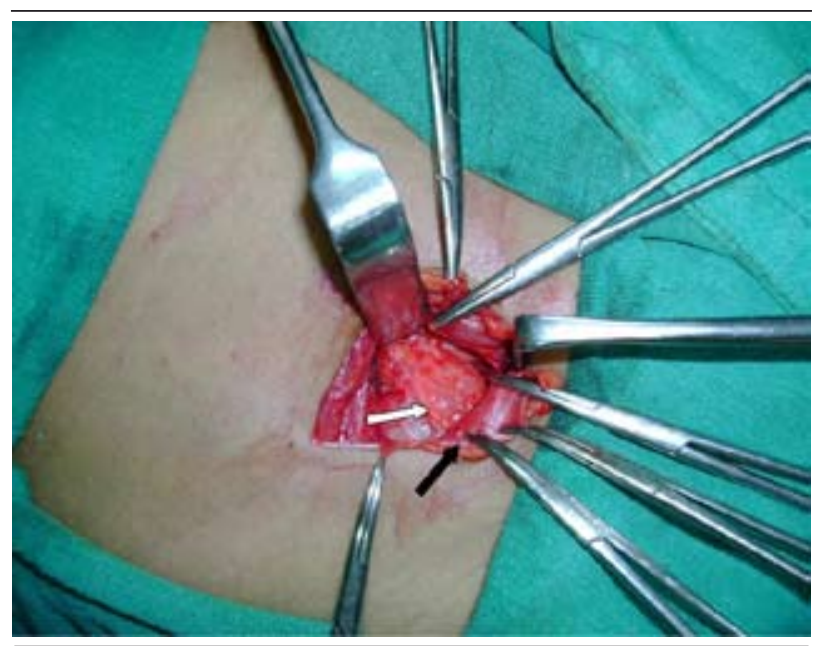

Figure 2. Operative photograph showing a thick hernia sac and extraperitoneal fatty tissue (white block arrow) entering the femoral canal. The inguinal ligament is reflected inferiorly (black block arrow).

\section{DISCUSSION}

Femoral hernias are rare in children. Most of the studies report an occurrence of less than $1 \%$ of all groin hernia. $2,3,5,10,11$ Historically Sir Astley Cooper described in 1827 the first two cases of femoral hernias in the paediatric age group in two girls. ${ }^{1}$ The etiology of femoral hernia is still a matter of discussion. ${ }^{1,2,4}$ McVay and Savage's hypothesis in 1961 that a congenital narrow posterior inguinal wall attachment onto Cooper's ligament with a resulting enlarged femoral ring is the important anatomic factor is still accepted by many. ${ }^{4,12-14}$ Others have suggested an acquired genesis related to increased intraabdominal pressure. However, in children with femoral hernias one rarely encounters processes which are responsible for increased intraabdominal pressure. ${ }^{1,4}$ The diagnosis of femoral hernia in children is still a challenging issue. In previous reports, the diagnostic accuracy ranged between $25 \%$ to $40 \%$ which increased to $90 \%$ by combining increased awareness and a careful examination of a hernia. ${ }^{6}$ Difficulty with diagnosis has been related to the rarity of the condition, inexperience of the surgeon, the more frequent occurrence of inguinal hernia, inadequate physical examination, and failure to look for a femoral hernia when no inguinal hernia was found. ${ }^{12,15}$ The case described above highlights that femoral hernias can be missed and underscores the importance of awareness in the mind of the surgeon. Needless to say that even in experienced hands, femoral hernias are often misdiagnosed as inguinal hernias. Several reports have documented that $40-67 \%$ of femoral hernias were incorrectly diagnosed preoperatively. ${ }^{5,15,16}$ This may be due to the rarity of femoral hernias, since the most common reasons for preoperative misdiagnosis are failure to consider such a diagnosis and inadequate examination. ${ }^{6}$ A femoral hernia should be suspected to make the correct intraoperative diagnosis when the surgeon encounters totally normal inguinal anatomy or a disproportionately small defect compared to the size of the preoperative bulge. In such situations, the normal inguinal floor should be incised to visualize the femoral canal. ${ }^{10}$ Various techniques have been described to repair femoral hernias extending from simple dissection and ligation of the hernial sac to complex plastic procedures. $1,2,4,10,16$ Recently, laparoscopic femoral hernia repair has also been reported. ${ }^{17}$ The use of laparoscopy, which is safe and feasible, allows all potential hernial orifices to be inspected for a hernia that may have been missed by open exploration, including defects in the contralateral groin. In conclusion the case report is further evidence to bring increased awareness to correctly diagnose femoral hernia either preoperatively or intraoperatively to avoid a nontherapeutic failed inguinal herniorrhaphy resulting in recurrence of hernia and possibly multiple interventions. 


\section{REFERENCES}

1. Ollero Fresno JC, Alvarez M, Sanchez M, Rollan V. Femoral hernia in childhood. Review of 38 cases. Pediatr Surg Inter 1997;12:520-52.

2. Fosburg RG, Mahin HP. Femoral hernia in children. Am J Surg 1965;109:470-5.

3. Fonkalsrud EW, de Lorimier AA, Clatworthy HW. Femoral and direct inguinal hernias in infants and children. JAMA $1965 ; 192: 597-9$.

4. Burke J. Femoral hernia in childhood. J Pediatr Surg 1967;166:287-9.

5. Immordino P. Femoral hernia in infancy and childhood. J Pediatr Surg 1972;7:40-3.

6. Marshall D. Femoral hernias in children. J Pediatr Surg $1983 ; 18: 160-2$

7. Maingot R. The choice of operation for femoral hernia, with special reference to McVay's technique. Br J Clin Pratt 1968;22:323-9.

8. Halvisson K, McVay GB. Inguinal and femoral hemioplastyA 22 year study of the author's methods. Arch Surg
1970;101:127-35

9. Nayeem N. Femoral hernia in chikken. Br J Clin Pratt 1990;44:383.

10. Anderas P, Jona JZ, Glicklich M. Femoral hernia in children. Arch Surg 1987;122:950-1.

11. Lickley A, Lavina H. Femoral hernias in children. J Pediatr Surg 1966;1:338-41.

12. Chapman WHH. Femoral hernia in children: an infrequent problem revisited. Mil Med 1991; 156:631-3.

13. Al-Shanafey S, Giacomantonio M. Femoral hernia in children J Pediatr Surg 1999;34:1104-6.

14. McVay CB, Savage LE. Etiology of femoral hernia. Ann Surg 1961;154:25-32

15. Zaman K, Taylor JD, Fossard DP. Femoral hernia in children. Ann R Coll Surg Engl 1985;67:249-50.

16. Radcliffe G, Stringer MD. Reappraisal of femoral hernia in children. Br J Surg 1997; 84: 58-60.

17. Lee SL, DuBois JJ. Laparoscopic diagnosis and repair of pediatric femoral hernia. Surg Endosc 2000; 14:1110-1113. 